\title{
Client perspectives on living with dysphagia in the community
}

\author{
Authors: \\ Simone R. Howells ${ }^{1,2}$ \\ BSpPath(Hons), GradCertClinEd \\ Petrea L. Cornwell ${ }^{1,2}$ \\ BSpPath(Hons), PhD \\ Elizabeth C. Ward ${ }^{3,4}$ \\ BSpThy(Hons), GradCertEd, PhD \\ Pim Kuipers ${ }^{1,3}$ \\ BA(Hons), MA, Grad Dip Rehab, PhD \\ Menzies Health Institute Queensland ${ }^{1}$ \\ Address: Griffith University, Gold Coast campus QLD 4222 Australia \\ School of Allied Health Sciences, Griffith University ${ }^{2}$ \\ Address: Griffith University, Gold Coast campus QLD 4222 Australia
}

Centre for Functioning and Health Research, Metro South Hospital and Health Service ${ }^{3}$ Address: PO Box 6053, Buranda QLD 4102 Australia

School of Health and Rehabilitation Sciences, The University of Queesland ${ }^{4}$ Address: St Lucia Campus, St Lucia QLD 4072 Australia

Keywords (6): dysphagia; lived experience; speech-language pathology; community; qualitative 
Author to whom all correspondence should be sent:

Ms Simone Howells

Speech Pathology program, School of Allied Health Sciences

Griffith University, Gold Coast campus

Queensland 4222

Australia

Phone: +61 756787663

Email: s.howells@griffith.edu.au 


\section{Abstract \\ Purpose}

Literature to date describing the lived experience of dysphagia has predominantly focused on the clinical populations of stroke and head and neck cancer. The current study aimed to understand the experience of people with dysphagia of varying aetiologies living at home in the community.

\section{Method}

Using a qualitative descriptive approach grounded in phenomenology, individuals with dysphagia were interviewed $(n=15)$ about their experiences living with and managing dysphagia at home.

\section{Result}

Thematic analysis revealed an overarching theme of "Journey of discovery-learning to live with dysphagia", which described the process of managing dysphagia at home. This theme was characterised by three subthemes: (1) The story of dysphagia; (2) Engaging with support networks; and (3) Limited community awareness of dysphagia.

\section{Conclusion}

This study highlights a range of psychosocial impacts individuals with dysphagia living at home may experience. Participants described how managing other health conditions alongside dysphagia influenced their perspectives about dysphagia. SLPs must consider individual client health priorities and provide support for not just the physical but also the psychosocial needs of clients. The reduced profile of dysphagia in our communities continues to be an ongoing barrier for clients with dysphagia and their families. 


\section{Introduction}

Physical consequences of dysphagia such as dehydration, malnutrition, and aspiration have been well-documented and understood by health professionals for many years (Carrión et al., 2017). Knowledge about the psychological and social impacts of dysphagia has been the focus of more recent studies, typically describing the patient's lived experience of dysphagia. However, gaps remain about how these psychosocial impacts manifest in heterogenous populations living with dysphagia, across different settings (e.g. acute, rehabilitation, community), and how speech-language pathologists (SLPs) can optimally support people with dysphagia and their caregivers across the care continuum.

In particular, the community setting has become a key context for the support of people with complex and chronic conditions such as dysphagia (United Nations, 2015). While it has been established that speech-language pathology (SLP) dysphagia care in the community requires a different approach to that of the acute setting (Howells, Cornwell, Ward, \& Kuipers, 2019a), community-based SLP services appear to be maintaining impairment-focused practices (Howells, Cornwell, Ward, \& Kuipers, 2019b). To determine how SLP services can best support community-dwelling clients with dysphagia and their families, it is important to understand the lived experience of people who are living with and managing their dysphagia at home.

The majority of the qualitative research describing the lived experience of people with dysphagia managing at home in the community has focused on two specific populations; post-stroke (e.g. Carlsson, Ehrenberg, \& Ehnfors, 2004; Helldén, Bergström, \& Karlsson, 2018; Jacobsson, Axelsson, Österlind, \& Norberg, 2000; Martino, Beaton, \& Diamant, 2010; Medin, Larson, von Arbin, Wredling, \& Tham, 2010; Moloney \& Walshe, 2018; Perry \& McLaren, 2003) and studies of patients with head and neck cancer (e.g. Larsson, Hedelin, \& Athlin, 2003; McQuestion, Fitch, \& Howell, 2011; Nund et al., 2014b; Ottosson, Laurell, \& Olsson, 2013). Literature exploring the experiences of people with dysphagia in other populations is scarce; our review found one in the Parkinson's disease literature (Miller, Noble, Jones, and Burn, 2006); one in the motor neurone disease literature (MND) (Lisiecka, Kelly, \& Jackson, 2019) and one incorporating a small range of groups including stroke and cancer not specified (Seshadri, Sellers, \& Kearney, 2018).

Across the studies conducted to date, some common themes have been reported. Physical changes relating to swallowing have been reported in most studies, though often appear linked to the condition. For example, the head and neck cancer studies noted physical changes due to cancer treatment (e.g. changes to taste as a result of chemoradiation) (Larsson 
et al., 2003; McQuestion et al., 2011; Nund et al., 2014b; Ottosson et al., 2013). In the one study of people with Parkinson's disease, physical changes were related to fatigue effects (Miller et al., 2006) while in the stroke literature, such changes were due to physically impaired structures (Moloney \& Walshe, 2018).

All reviewed studies found people with dysphagia reported a range of psychosocial issues, suggesting the psychosocial impacts for the person with dysphagia are as significant as the physical impacts. Accordingly, it may be inferred that health professionals working with clients with dysphagia must also understand and respond to these psychosocial issues as part of usual care, which may pose a challenge for community-based SLP dysphagia services (Howells et al., 2019b). Firstly, participants in the studies to date described a raft of negative emotional responses such as feelings of fear, panic, loss, hopelessness, frustration and embarrassment (Jacobsson et al., 2000; Larsson et al., 2003; Lisiecka et al., 2019; Martino et al., 2010; McQuestion et al., 2011; Medin et al., 2010; Miller et al., 2006; Moloney \& Walshe, 2018; Nund et al., 2014b, 2014c; Ottosson et al., 2013). Other participants spoke of feelings of hope and survival (Helldén et al., 2018; Jacobsson et al., 2000; Larsson et al., 2003; Moloney \& Walshe, 2018; Ottosson et al., 2013; Perry \& McLaren, 2003). Participants across a number of studies also identified lifestyle changes as a result of dysphagia including less frequent social outings or substantial changes to the nature of outings (McQuestion et al., 2011; Medin et al., 2010; Miller et al., 2006; Moloney \& Walshe, 2018; Ottosson et al., 2013; Perry \& McLaren, 2003). Some studies described how participants withdrew from social interactions involving food altogether; for those with MND, this was due to fear of choking or reduced stamina (Lisiecka et al., 2019) while for those following head and neck cancer treatment, this was due to feeling embarrassed about changes to the way they ate (Larsson et al., 2003). Eating only with family was seen as a preferred option for many (Medin et al., 2010; Ottosson et al., 2013; Seshadri et al., 2018). Research has also highlighted the lack of understanding that exists within the community about dysphagia. Studies by Ottosson et al. (2013) and Nund et al. (2014b, 2014c) in the head and neck cancer literature and Medin et al. (2010) in the stroke literature described the difficulties experienced by people with dysphagia to eat in the company of friends or at restaurants due to limited food options and lack of acceptance of certain mealtime behaviours (e.g. coughing). This lack of understanding has also been reported to include health professionals (Ekberg, Hamdy, Woisard, Wuttge-Hannig, \& Ortega, 2002; Helldén et al., 2018). Such widespread lack of awareness about dysphagia raises important questions about how clients can be optimally supported in their communities and in the healthcare system. It also highlights the important role SLPs can play in advocacy 
for people with dysphagia and in the education of significant others and the general community.

Although existing studies have identified a number of important issues, a range of limitations can be identified. Helldén et al. (2018) noted that most studies exploring client perspectives following stroke have focused on the first six months post-stroke rather than longer term impacts for those living with more chronic dysphagia (e.g. Jacobsson et al., 2000; Medin et al., 2010; Moloney \& Walshe, 2018; Perry \& McLaren, 2003). Other studies have utilised very small sample sizes of five or less participants (Carlsson et al., 2004; Helldén et al., 2018). Further, only three studies have explored the lived experience of dysphagia beyond either the stroke or head and neck populations, despite the recognised diversity in client groups that community SLP dysphagia caseloads are known to reflect (Howells et al., 2019b; Rumbach, Coombes, \& Doeltgen, 2018). Therefore, it is timely to document a broader view of the issues that may affect a range of people with dysphagia living at home in the community.

The aim of the current study was to understand, from the perspective of people with dysphagia caused by various aetiologies, the experience of managing dysphagia at home. The research team specifically sought to understand how dysphagia impacts on the lives of adults living at home and to identify what they perceive as the barriers, enablers and key issues to managing their dysphagia. It is proposed that obtaining an in-depth understanding of the experiences of people with dysphagia from a variety of aetiologies will inform priority setting for SLPs working with dysphagia in the community and will ultimately support the design of SLP services to more holistically meet the increasing needs of clients living at home in the community.

\section{Methods}

A qualitative, descriptive approach grounded in phenomenology as described by Sandelowski (2000) and used in the area of dysphagia by Nund et al. (2014c) was adopted. Ethical clearance was provided by the relevant health service and university human research ethics committees.

\section{Participants}

Clients with dysphagia aged $\geq 18$ years of age, living at home in the community, receiving their primary mode of nutrition and hydration orally and with adequate English, cognitive and communication abilities to participate in an interview were recruited. Recruitment occurred through public and private SLP services as well as through media coverage regarding the 
primary researcher's program of research. Cognition was screened prior to the interview using the Mini Mental State Exam (MMSE) (Folstein, Folstein, and McHugh, 1975) and all participants scored $\geq 20$.

A total of 22 adults with a known diagnosis of oropharyngeal dysphagia provided consent for the researcher to contact them about the study. Five subsequently declined to participate and two were ineligible to participate. The remaining 15 adults were recruited into the study. Participants were predominantly male (five female) and ranged in age from $30-93$ years with a mean of 71.7 years $(S D=14.4)($ Table I). Thirteen of the 15 were aged $\geq 65$ years. In total, the study recruited five participants with dysphagia of cerebrovascular aetiology, seven with a progressive neurological condition (six with Parkinson's disease and one with multiple system atrophy-cerebellar), one with dysphagia due to general ageing, one with a history of base of tongue cancer and one who had sustained a jaw fracture and was living with long term impacts to eating and drinking. Further information about each participant's demographics relevant to their dysphagia is contained in Table 1. This information was collected by the researcher immediately following the interview.

Further information about each participant's demographics relevant to their dysphagia was collected by the researcher immediately following the interview and is contained in Table 1. Participants completed a Dysphagia Handicap Index (DHI) (Silbergleit, Schultz, Jacobson, Beardsley, \& Johnson, 2012), an Eating Assessment Tool (EAT-10) (Belafsky et al., 2008), and an Assessment of Quality of Life (AQOL-8D) questionnaire (Richardson, Iezzi, Khan, \& Maxwell, 2014). Reported dysphagia handicap on the DHI varied between participants, ranging from no handicap to severe handicap, while all except two participants reported experiencing dysphagia symptoms on the EAT-10 (where a score of $\geq 3$ indicates presence of dysphagia). The AQOL-8D scores reflect variability in the quality of life impacts participants were living with at the time of interview across a range of domains including independence and mental health, with higher scores suggestive of greater quality of life impact.

\section{Table I about here}

\section{Procedure}

Interviews were conducted face-to-face by the primary researcher in the participant's own home except for one participant (Participant 5) who attended the interview at the university. Using an interview guide, participants were asked about their experience of living with dysphagia, their perceptions of how they had adjusted, and they were asked to describe barriers, enablers and key issues they had experienced when managing dysphagia at home in 
the community. The interview guide ensured the primary researcher covered relevant topics during the interviews with questions adapted where appropriate during the interview to ensure conversational flow (Patton, 2015).

Interviews lasted between 22 minutes and 1.5 hours and were audio recorded to enable accurate transcription. Following each interview, the primary researcher kept a reflective journal to support transparency in the research process (Ortlipp, 2008). As the journal entries contained summaries of participant experiences, they also assisted in recognising when data saturation had occurred; that is, when no new information was generated from subsequent interviews (Fusch and Ness, 2015). This occurred in the last 4-5 interviews.

\section{Data Analysis}

Thematic analysis was undertaken as described by Braun and Clarke (2006). The primary researcher began by reading the interview transcripts several times to become immersed in the data and initial impressions were noted (Braun and Clarke, 2006). Independent open coding of two transcripts by the primary researcher and a member of the research team not involved in the interviews occurred and the two researchers met to establish consensus on the codes (Elliott, 2018). The primary researcher then analysed the remaining transcripts, adding and refining codes when new insights were evident in the transcripts (Braun and Clarke, 2006). At the conclusion of coding, the primary researcher also re-coded a clean transcript from early in the coding process to ensure consistency in coding across time (Elliott, 2018). During a meeting with the research team, the final list of codes was grouped and categorised into one overarching theme, three subthemes and several categories. Comments made by participants that resonated with the categories were noted and attributed to the participant's identifier to ensure trustworthiness of the data (Braun and Clarke, 2006). All participants were provided with a written summary of the main research findings and asked to provide feedback. Eleven of the 15 participants provided feedback, and all confirmed the researchers' interpretation of their experiences.

\section{Results}

Thematic analysis revealed one overarching theme and three corresponding subthemes which described the participants' experiences of managing dysphagia at home. The overarching theme of 'a journey of discovery - learning to live with dysphagia' described the journey participants had embarked on since becoming aware of dysphagia and its symptoms, detailing the various discoveries they made in their adjustment to life with dysphagia. Specifically, 
their journey included three key subthemes: (1) the story of dysphagia; (2) engaging with support networks; and (3) limited community awareness of dysphagia. Each subtheme contains categories that further elaborate on the participants' views.

\section{Subtheme 1: The Story of Dysphagia}

Participants described their personal stories about their dysphagia journey, detailing their swallowing difficulties and how these have impacted them in their day to day functioning. Through these stories, they shared their experience of managing dysphagia in the context of other health issues, the losses and changes dysphagia had caused for them, their discovery of solutions to support successful mealtimes and their experiences of managing dysphagia outside the home, either at other people's homes or in cafes and restaurants.

\section{Managing dysphagia within the context of other health issues}

All participants described their current swallowing difficulties, highlighting their own awareness of the physical impairments dysphagia had caused. Some participants described the onset of dysphagia symptoms (e.g. coughing) but did not realise this was an issue until becoming unwell: I'd started to do a bit of coughing ... then when I got pneumonia, we discovered [dysphagia] (P12). Some described their swallowing difficulty in anatomical terms informed by videofluoroscopic swallowing study (VFSS) findings: When I swallow, I get a tiny bounce into the larynx and have to cough every time, many times (P7) while others described what they thought was occurring for them: I tend to swallow around the side of my tongue ... then I throw the head backwards to get the last bits down my throat so usually I can hardly drink a cup of water without coughing. I cough quite badly. And I've had a bit of trouble lately with swallowing solids (P6). Participants also described a range of ways they minimised risk and maximised safety when eating and drinking using self-taught strategies. These included eating/drinking slowly, having small amounts, not talking during intake and chewing food 'properly': I keep clearing my throat of saliva and I have to be content with swallowing more slowly. I just swallow more deliberately and I have to be careful I don't choke myself... Don't swallow too fast or too much at a time (P2). For participants reliant on medications to manage their symptoms such as those with Parkinson's disease, timing of medications and mealtimes was important: The main thing about my swallowing is ... eat around when my tablet's working ... (P5).

Related to the physical manifestation of dysphagia, all participants were living with dysphagia alongside other health issues and spoke about dysphagia in the context of these other issues. For most, their experience of dysphagia was difficult to separate from broader 
health issues. This was particularly apparent for those who were living with progressive neurological conditions and experiencing disease-related challenges or those post-stroke with residual limb weakness as both directly impacted upon their mealtime experience. For example, reductions in fine motor skills were noted: My fine motor skills are not as good as they were. Just handling a knife and fork, yeah. Loss of dexterity ... Even if I'm hungry, I find I spend most of the time trying to cut a piece off (P3). Challenges with balance and mobility also impacted on mealtimes: It's [cooking] a bit of a drag.... Cheese on toast or beans on toast, (I have) probably a bit more than I should do. Especially when you're not feeling well and you can't hardly move your leg (P5).

For many, managing a number of complex health issues made their dysphagia feel like a lower priority, perceiving that other challenges such as mobility difficulties impacted on their lives more than dysphagia. As described by Participant 3: One of the problems with Parkinson's is trying to manage the things that give you the most grief and I'd say swallowing is probably at the lower end. Participant 9 described how, when dealing with several health issues, managing dysphagia became 'just another thing' to manage: $I t$ [dysphagia] hasn't really affected me. I guess, because of the amount of health issues I've had, it's just kind of another thing. There was also a sense among the participants who had had a stroke that their dysphagia was improving whereas some of their other health issues were not. This further reinforced why dysphagia was a lower priority for them: They're [swallowing difficulties] probably the least of my worries. I feel like they're getting better. But some other problems aren't getting any better (P11). However, one participant whose dysphagia diagnosis was new and directly related to her progressive neurological condition described dysphagia as significant in the context of her health condition: It [dysphagia diagnosis] has been a milestone for me in this illness and it scared me because I could kind of see a downhill pathway ... and I don't know how fast that downhill pathway goes (P13).

\section{Loss and change}

Emotional responses to dysphagia were described by participants and focused on their experience of losses and changes they had employed to accommodate the losses. Describing the immense loss dysphagia can cause, one participant summarised: I eat to live, I don't live to eat anymore (P15). Living with dysphagia caused participants a range of emotional responses which underpinned the loss and change they experienced. These included feeling embarrassed and self-conscious when eating in front of others: When I'm chewing ... it's not like other people. If I'm eating a meal with others, I keep wobbling my lips which is a bit of an embarrassment (P2). Fear, hopelessness, and despondence were all emotional responses 
described by participants, particularly for those who felt their dysphagia was more permanent and / or worsening. Participant 8 , who was managing dysphagia in the context of Parkinson's disease, described feeling fearful initially: It was terrifying, because all of a sudden I couldn't swallow and I didn't know what to do but noted that over time she thought: I'd rather live with fear or else I won't be able to eat. Other participants felt a sense of hope that their dysphagia would or had begun to improve, which was particularly apparent among those accessing regular SLP sessions and / or doing swallow rehabilitation exercises: I think I'm improving with the coughing. My own little aim is to get the muscles in here good enough not to worry about the thickening (P1).

Participants described losses of certain foods/drinks, often mentioning foods they missed: I tend to avoid the big thick burgers but I love them (P5). These losses were also described in the context of special occasions, such as Christmas: Christmas was a bummer for me because you can't eat all of the things you'd have at Christmas (P12). Losses also extended to lifestyle activities. For example, Participant 9 described how having dysphagia meant the loss of her previous interest in cooking: I used to love cooking and now because I don't eat a whole lot, (I'm) just not interested. Loss of mealtime convenience was described by Participant 13 when she explained the challenge of managing dysphagia when one is not ' $m u c h$ of a cook'; in the past she said she would call an Uber or Deliveroo or something if I'm tired but I can't do that anymore.

Loss of and changes to social interactions because of dysphagia, particularly outside the home, were also apparent. For example, Participant 8 opted to no longer eat at the local club: I stopped going down there because I didn't want to embarrass him [husband]. From the perspective of a younger person with dysphagia, Participant 9 acknowledged: What I do miss, is going out and having a meal with someone and having a drink. When describing an experience after leaving a restaurant where she was unable to find anything suitable to eat on the menu, one participant shared: I was crying when I walked down the road. And I cry now because I thought this was my moment, and I realised that life was never going to be normal again. Ever. Everywhere I was going to go and eat, I was going to have a problem (P15).

Many participants described the change in their thinking that had occurred as a result of dysphagia, where they spoke of having a constant awareness of both dysphagia and its risks: I think about it [dysphagia] all the time, you've got to be aware of it... you have to think about what you do, you can't just sort of rip in (P6). Participants also identified the need to consider the impact of dysphagia on those around them: It's been ... a massive change. In 
your thinking about what foods you're gonna cook each day. Everything revolves around it... And you gotta think about whether anybody else in the house can eat it (P12).

\section{Finding solutions for mealtime success}

Overwhelmingly, participants were aware of the foods/drinks that caused them swallowing difficulty and described ways they had attempted to still enjoy these items by making adaptations. For example, by softening hard foods through dipping in a hot drink: Biscuits ... I can dunk them. If I dunk them they're good but you can't do that when you're out (P12), peeling the skin of fruit/vegetables: If I ate an apple without peeling it, bit of skin would catch in there [points to throat] very easily. So now, if I had an apple I would cut all the skin off and cut it up to masticate it ... to you know, very small pieces (P1), or by changing the way food was cooked: I like my steak well done so it tends to be a bit harder. So I've tried to come down to medium well done now, to make it a bit easier to eat (P5). Attempts at meal variety beyond the 'traditional' safe foods were not always successful: I tried making gnocchi but whether I didn't cook it enough, I bought some ready-made gnocchi and it was so rubbery that I haven't tried again (P15).

For participants responsible for their own food preparation and cooking, finding dysphagia-friendly recipes proved a challenge: I've sourced simply soft food (recipe) books but ... they're very basic and kind of a bit old fashioned... Mostly for older people... it's more like rest home food (P15). Sourcing ingredients and going grocery shopping was also a process of discovery: My process has been, what foods do I actually like that I can have, that's number one. Then make sure that I go shopping and have giant lists and that it's [the pantry's] stacked... like tins of baked beans work fine so make sure I've got lots of them... Make sure you've got all this stuff there so you don't get caught (P13).

\section{Managing dysphagia outside of the home}

The process of managing dysphagia outside of the home at family and friend's homes, restaurants and cafes was something all participants discussed. Many found ways to enjoy food/drink outside of the home and described a range of strategies they employed to minimise the negative impact dysphagia could have on their experience. For example, seeking out a table where people would not be able to observe the person with dysphagia: What I tend to do is sit and eat in less conspicuous places. Like, if I can sit in the corner somewhere facing the window... I feel a bit more comfortable than people watching me (P5). Avoiding ordering certain foods was also a key strategy: I'll still go out with the family and have a meal, it's just limited. Like, I'd never eat steak (P9). Others described sticking to foods they knew were 'safe' such as cake and coffee rather than a main meal: I've never eaten so much soft cake. 
Just plain cake, like sponges and cream or cake and custard. That's what I found ... the easiest; and then didn't have to worry about swallowing and didn't have to worry about chewing (P14) or going to food outlets that would have a large range of options, such as a buffet: We go to[the club]. They have a buffet smorgasbord meal and I can go around there just picking and choosing (P15). Ordering items not listed on the menu was also a strategy that had been trialled with success: I kept staring at it (the menu) thinking 'oh dear!'. But I asked them eventually ... I said 'do you do omelettes?' ... and they said they would (P13).

Participant 9 described how she managed social situations with friends involving eating: I'll sort of just go to their place and I won't eat in front of people. I'll go there and have chips and nibblies as opposed to sit there and have a meal with them. Participant 9 was also the only participant to be working outside of the home. She described the changes needed to lunchtimes to manage dysphagia at work: I'll go out for lunch, make a point of now going out. Whereas prior to this, I'd sit at my desk and I'd eat a big bowl of salad and of course, now I just wouldn't touch something like that. Another participant described the challenge of going to industry lunches where dysphagia was not catered for and the unknown of whether lunch would be something he could consume: I still go along to industry meetings ... the food comes out in a typically alternative drop ... sometimes you don't know what (you'll get) (P3). Some participants described how, no matter where they went or what they ordered, their dysphagia was still going to impact the experience: You can't just go out to dinner and have a meal. There's some places you can go but I still (*cough*), I gotta cough after I eat... Each time you swallow (P12).

\section{Subtheme 2: Engaging with support networks}

Participants described the support they had received from family and friends, health professionals and their peers regarding their dysphagia and associated health condition(s) including practical, emotional, and social support. Overwhelmingly participants identified that the supports they had received were positive and valued. On occasion, participations identified ways family and friends, health professionals, and peers could further support them.

\section{Support from family and friends}

Participants described the many and varied ways their family and friends had supported them and their dysphagia. All participants described the appreciation they felt when family and friends cooked for them and was especially appreciated by those living on their own: $M y$ sister has started making me some pre-done frozen meals... when she makes them, she makes 
sure they're cut up small and stuff, because she knows how I'm supposed to eat them. Then I just heat them up and they're much easier as well (P5). Many participants also described how some friends willingly prepared dysphagia-friendly meals: The first time I went there, she made this gorgeous little omelette. She cut up smoked salmon into the tiniest pieces and she made a little avocado salad, it was terrific! And since then, she just puts her head on it (P13). Others acknowledged that while friends making a dysphagia-friendly meal was helpful, they lacked knowledge of what to make, and often made the same thing: People bring a lot of lasagnes which are pretty soft but you don't want them every day of the week (P6).

\section{Support from health professionals}

SLPs were among the most discussed health profession that participants described in relation to their dysphagia. However, several participants openly acknowledged they did not understand the SLP role in dysphagia: I didn't know they [SLP] had anything to do with the swallowing (P6). Indeed other participants described an incidental process of linking with SLP services for dysphagia: Initially I went there [SLP] because I thought I needed to improve my speech and then we had a discussion about swallowing and from then on, we actually continued with the swallowing part... that was a very good outcome for me (P7).

Participants shared aspects of SLP services that had been particularly useful and valued by them. This included having VFSS studies explained to them (We went through it [VFSS clip] all again on the small screen ... she could show me slow motion what was going on and I was asking questions... and she came up with the answers all the time so I was very happy with all of that (P12)) and going 'above and beyond' for participants. For example, Participant 13 shared how her SLP had supported her overseas travel plans in the context of dysphagia: We're going to Japan shortly and [SLP] has been giving me advice on that... She downloaded a menu from a Japanese restaurant in [participant's hometown] ... And then went through it with me saying 'tick, yep, that might be worth trying, nup, wouldn't go near that. '... I just thought that was just really useful, functional (P13). Another participant shared an example of SLP dysphagia care that she highly valued: One day I was down, she bought flour, butter and we made a cake together. And I tell you what, it was worth a million dollars... it just made my day (P8). Some participants identified ways that SLPs could better support them to manage their dysphagia, such as practical information about what to eat and how to cook it: Something that would help ... is some information like a list offoods, the methods for making ... and a list of things you can do... The speech therapy is really good but, bit more things on how to eat and swallow, and things that are supposed to help it (P5). 
Other allied health professionals (e.g. dietitians) were also described as a source of information and support for living with dysphagia. Participant 12 shared how working with a dietitian was particularly helpful for him: Talking to her and explaining what was happening and how I was trying to manage it, we've worked out a plan [foods for dysphagia] between us which has been very good (P12).

\section{Support from peers}

Some participants described how people experiencing the same health condition (e.g. Parkinson's disease) had been a source of support for them. Attending local groups, such as a stroke or Parkinson's disease support group, helped them with their health condition as well as the associated issues related to dysphagia: We laugh about it [eating challenges] more than anything... other people have got the same symptoms as me... You share each other's experiences... my symptoms are normal for Parkinson's. Makes you feel better straight away (P5). Peer support also provided opportunities to share tips and tricks and the friendships made in peer groups transcended the group for some: we swap information ... it's picking up those things that might make your life a little easier (P3). One participant described being linked with a disease-specific peer group and initially refusing, but then had begun to reconsider as her disease progressed: When I was first diagnosed I said "no thank you, I don't really want to." But I have since found myself looking up other people with MSA because it's rare-ish. (P13). Other participants shared how they had not been linked in with or offered to be linked in with a peer group but felt this would have been helpful: I've learned for myself but it might have been nice just for someone to come past ... saying 'I had this problem and if you do everything you're told, you'll get through it' (P14). As one participant summarised, peer support focused on the practical aspects of managing dysphagia would be more valuable than discussing psychological issues: I don't want to talk about how this makes me feel or mental issues or anxiety about it, I'm not interested... I would like to talk about what recipes they've come up with and where do they shop and is there anybody who delivers good stuff you know? (P13).

\section{Subtheme 3: Limited community awareness of dysphagia}

The lack of awareness of dysphagia within the community was something participants raised. This was apparent to them across the spectrum of their community, from friends and the general public, to experiences with some health professionals and the hospitality industry when attempting to manage their dysphagia outside of the home. Overwhelmingly, they felt 
others did not know what dysphagia was, did not understand the significance and did not know how to accommodate for required diet and fluid modifications.

\section{Awareness among friends and the general public}

Participants lamented a general lack of awareness about dysphagia among their friends and in the general public: They don't understand very well (P5). However, in some cases, friends had become aware and knowledgeable about dysphagia through participants sharing information and discussing dysphagia openly. This was particularly relevant if the person with dysphagia was dining with family and friends, or if family and friends were cooking for them. Participants attempted to educate friends and others about dysphagia by sharing information such as handouts: I have a friend who's actually a great cook and I go to her place for dinner quite frequently... I just sent her the list of do's and don'ts... (P13). But even when friends were able to accommodate dysphagia, other challenges arose when dining socially. Some felt they needed to explain why they were eating something different: $O n$ other occasions there have been other people there and I just sit up eating my stuff and a couple of times I've just gotten embarrassed and said "I've got this swallowing problem so [friend is] doing something special for me" (P13). Others took a more private approach, preferring not to share aspects about dysphagia and its impact: If I meet someone, it'll be for a shorter time and I don't make a point of saying why... A lot of my friends are big drinkers, so I don't think they understand. Well, they wouldn't understand why I'm not drinking... I'm a very private person so I just don't go there (P9).

Many participants described a self-consciousness about what others thought about them and their eating/drinking requirements, especially when outside of the home, because of lack of public awareness and understanding: You're more worried about what people are going to think looking at you right? We went for example for my birthday ... I noticed people looking out of the corner of my eye, looking at me because I still look fairly young and people think you're drunk (P5). Some described feeling judged by friends of friends (At one of these dinners that I did go to with my very good friend, there was somebody there that was not impressed... I think this person thought I was being pernickety or precious in some way (P13)) and even by friends on occasion (Some of my friends ... I don't know whether they get a little bit impatient ... particularly the one that said "just order it, just forget about it!" (P15)). Naturally, participants found this lack of awareness and understanding by others frustrating: Some think it's [dysphagia's] a lot of fuss about nothing and I just want to say “walk in my shoes!” (P15).

\section{Awareness among health professionals}


Participants also noted a lack of awareness of dysphagia among medical professionals, including general practitioners, ENTs and maxillofacial surgeons: My ENT ... he sort of doesn't really get the whole swallowing thing, the importance of it, I don't believe (P9). Participants shared anecdotes of seeking information and advice from their medical specialists about dysphagia and being disappointed with the outcome: When it [dysphagia] first happened to me, my first question to [maxillofacial surgeon] was "what is a soft diet?" ... I didn't have any idea. What he said to me was "oh, use your imagination with pasta." That was all he said. He had no literature, no advice (P15). In some cases, this lack of understanding led to participants feeling their concerns were dismissed: I went "I've got this swallowing problem now and I'm so concerned about going to Japan. Can I go to Japan? What do you think?" and [neurologist] said "of course you can go to Japan, what's the problem?!” (P13).

\section{Awareness within the hospitality and food industry}

Participants who continued to socialise over food and drink outside of the home drew attention to the lack of awareness about dysphagia in the hospitality and food industry. This affected them emotionally and financially, and was rarely a positive experience: They [restaurant] tried (to accommodate dysphagia) but they don't understand, not really... I've thought 'well, why am I going to spend \$20-30 on something and find I can't eat it?' (P15).

Some participants described looking up restaurant menus before visiting to ensure an appropriate food option was available, however this was not always successful: We looked up the menu on the internet (and) I saw that they do breakfast. So, I thought, omelette, lovely. So, we got up there at half past 12 and I said, "can I have an omelette please, I have a problem with my chewing" and she said "oh, breakfast finished at 12 ... I'll ask the chef" and I could see him... "no breakfast is off. I'm not cooking omelettes for anybody" (P15). For some, attempts to educate hospitality staff in local communities also proved frustrating: $I$ went to the bowls club here, they've got a new chef... I said, "do you think you could put one soft food recipe option on your menu?" (and he said) "no I don't think so but if you phone me a couple of days before you come in, I'll make sure there's something you can eat'" (P15). It was apparent that even in instances where staff were understanding and made menu suggestions to accommodate the person with dysphagia, they did not understand the specific dietary requirements: [waitress] said "oh you'll be able to eat the gnocchi" and I could eat most of it but I had to pick out the prosciutto. There's always something in there that you can't (eat) (P15). The same participant, who lead a very active social life, also went on to describe another occasion where the information about her dysphagia requirements did not 
filter through to the chef accurately: Another occasion, [waitress] talked to me and listened to everything but by the time the chef got the message, he obviously didn't read or hear or know; and I had the normal raw tomatoes, raw spinach and this hardest sourdough (P15). Managing dysphagia while travelling was also identified as a challenge for some due to lack of awareness in the travel industry. For example, the lack of awareness of and accommodation for dysphagia by airline companies was noted by Participant 15: My daughter in law tried to get them [airline] to see if we were going to have soft food on the aeroplane and she was told "no, baby food, that's all."

In summary, most participants wanted access to suitable dysphagia-friendly options at cafes and restaurants: I mean, (I want) restaurants for people (with dysphagia) ... [and] home delivery food that is attractive and tasty and deals with the different (texture modified) levels (P13). Some also expressed wanting to buy suitable ready-made, packaged meals: I think for perhaps some ready-made meals... they're easier to cook and reheat, a bit like respite for cooking. Just a few days where we don't have to worry about what to eat and stuff (P5).

\section{Discussion}

This study has provided insights into the journey of discovery a person with dysphagia may experience when living at home in the community. Participants described their personal stories of dysphagia, the value of their support networks and the impact that limited community awareness of dysphagia had on them. Consistent with previous literature on the lived experience of dysphagia, participants in the current study demonstrated an awareness of the physical dimensions of dysphagia and their associated swallowing problems (Larsson et al., 2003; McQuestion et al., 2011; Miller et al., 2006; Moloney \& Walshe, 2018; Nund et al., 2014c; Ottosson et al., 2013). Interestingly and in contrast to earlier studies, participants in the current study emphasised the importance of the health issues they were managing alongside dysphagia. Many described these other health issues as being of the same or a higher priority than their swallowing difficulties. This may be due to the current cohort having a milder dysphagia presentation, characterised by making minimal diet and fluid modifications. The current participants were also older and therefore more likely to be managing more complex and chronic health conditions, and just under half were managing a progressive neurological condition. Therefore it is probable that participants' focussed their accounts on the area of most concern to them (their broader health condition), as did the participants in a recent study which investigated the experience of people with dysphagia due to MND (Lisiecka et al.,2019). The different emphases across populations highlights the 
importance of all SLPs taking a holistic and client-centred approach to recognise where clients are in their dysphagia and health journey, especially for those living at home in the community. It is clear from these findings that different clients will have differing health needs and priorities and it would be erroneous to assume dysphagia is always the most salient.

The journey of discovery illustrated by participants in the current study is akin to the concepts of finding a 'new normal', 'finding new ways' or 'learning to manage' as previously described in the lived experience of dysphagia literature, across both the head and neck cancer and stroke populations (Carlsson et al., 2004; Helldén et al., 2018; Larsson et al., 2003; McQuestion et al., 2011; Medin et al., 2010; Ottosson et al., 2013; Perry \& McLaren, 2003). Consistent with previous findings, participants in the current study described their trial and error process of finding foods/drinks they could safely consume (Carlsson et al., 2004; Helldén et al., 2018; Ottosson et al., 2013), use of mealtime strategies such as different postures and utensils (Carlsson et al., 2004; Helldén et al., 2018; Medin et al., 2010), and challenges they had experienced with managing dysphagia outside the home (Perry \& McLaren, 2003; Seshadri et al., 2018). It can be surmised that participants with dysphagia irrespective of cause, are likely to undergo a process of discovery to adjust to life with dysphagia at home. How SLPs can best support them through this process warrants further investigation however, possessing an awareness of the practical strategies that existing clients have found useful, may be a valuable starting point.

Participants in the current study emphasised the networks they drew on for support to manage their dysphagia and broader health conditions. These supports included family and friends, health professionals, and peers, and encompassed practical, social, and emotional supports. The important role of support from others when managing dysphagia has been described by a number of studies across both the stroke and head and neck cancer populations (Larsson et al., 2003; Medin et al., 2010; Moloney \& Walshe, 2018; Nund et al., 2014b; Ottosson et al., 2013). It is apparent the support of family, friends, and health professionals are central to a person with dysphagia's journey and SLPs must include these valued networks as part of routine dysphagia care in the community.

The current participants described a lack of awareness, knowledge, and understanding about dysphagia, its risks and about texture-modified food and fluids within the broader community. This lack of awareness was found in the general public, in the hospitality industry, and, alarmingly among health professionals. While the need to better inform health professionals has been identified previously (Ekberg et al., 2002; Nund et al., 2014b), the 
current study specifically found a lack of awareness among medical professionals. There would appear to be a need to inform all relevant general and specialist physicians about both dysphagia and texture-modified diets. As recent as 2018, participants in the Helldén et al. (2018) study reported receiving little or no dysphagia support from doctors or nurses with SLPs the only health profession involved in their dysphagia care. Further, participants in the Carlsson et al. (2004) study described feeling doctors and nurses lacked competence in dysphagia. Based on the current and previous findings, there is a need for SLPs to share dysphagia information among multidisciplinary colleagues through new and innovative ways to ensure clients can be supported sustainably and optimally in the community.

Finally, there would appear to be limited understanding of dysphagia and related dietary requirements across the hospitality sector. Only in the aged care sector are chefs expected to possess knowledge and skills in preparing texture-modified foods and fluids, due to aged care accreditation and funding requirements (Bartl \& Bunney, 2018) Staff in the broader hospitality industry are not required to accommodate for dysphagia in restaurants and cafes but it is clear from the current study and others (Farri, Accornero, \& Burdese, 2007; Nund et al., 2014c, 2014a; Threats, 2007) that this would be well received by clients and families alike. Recognising that chefs may have limited understanding of dietary requirements related to more common health conditions such as coeliac disease (Karajeh, Hurlstone, Patel, \& Sanders, 2005) raises questions about how hospitality staff can be trained to accommodate dietary requirements, including texture modified diets. Further research exploring hospitality industry awareness and knowledge of dysphagia and texture modification is an important first step in reducing stigma and enabling people with dysphagia and their loved ones to be able to once again enjoy the social custom of eating and drinking outside of the home.

\section{Limitations and Future Directions}

This study has provided several new insights into what is known about the lived experienced of people living at home with dysphagia. Participants recruited were managing dysphagia that appeared functionally mild as evidenced by the requirement for minimal diet and fluid modifications. Therefore, the perspectives in this study may not directly reflect those of people living with dysphagia considered more severe. Participants were predominantly aged $>70$ years and it is hypothesised that younger people managing dysphagia may differ in their experiences. Further research exploring issues that younger people managing dysphagia may experience is warranted. Finally, data in the current study were collected at a single time 
point. Engaging with individuals at multiple time points across the dysphagia journey would be beneficial to better understand the process of adjustment and how SLPs can target support accordingly.

\section{Conclusion}

The current study has highlighted a number of psychosocial impacts dysphagia may have on an individual. For the participants in this study, managing dysphagia alongside complex and often multiple health conditions put dysphagia in perspective. Dysphagia created a range of losses and changes in the lives of participants and required them to find ways to manage challenges such as what to eat/drink and how to socialise outside of the home. Participants drew upon a range of support networks in their management of dysphagia. It was clear that the lack of awareness of dysphagia in the community, including the hospitality industry and in the health care they had received, had an adverse effect on them and highlights the important role SLPs can take in raising the profile of dysphagia and texture-modified diets within society. There is a need for SLPs to support people with dysphagia during all stages of their healthcare journey, maintaining a focus on not just the physical aspects of dysphagia, but the psychosocial and practical aspects as well. By taking a holistic and client-centred approach that considers the differing health needs and priorities of clients, SLPs will be better able to meet the needs of people with dysphagia living at home in the community now and into the future.

\section{Acknowledgements}

The authors wish to acknowledge the inspiring participants in this study who so openly shared their experiences for research. Thanks also go to research assistants, Pooja Gandhi, Judy Yushan Su, Lauren Rodgers, Maddison Napier and Laura Rainey who assisted with transcribing the interviews.

\section{Declaration of interest}

The authors report no conflicts of interest. The authors alone are responsible for the content and writing of the paper. 


\section{References}

Bartl, R., \& Bunney, C. (2018). Best practice food and nutrition manual for aged care homes (2.1). Gosford, N.S.W.: Central Coast Local Health District, Nutrition Department. Belafsky, P. C., Mouadeb, D. A., Rees, C. J., Pryor, J. C., Postma, G. N., Allen, J., \& Leonard, R. J. (2008). Validity and Reliability of the Eating Assessment Tool (EAT10). The Annals of Otology, Rhinology \& Laryngology; Thousand Oaks, 117(12), 919-924.

Braun, V., \& Clarke, V. (2006). Using thematic analysis in psychology. Qualitative Research in Psychology, 3(2), 77-101. https://doi.org/10.1191/1478088706qp063oa

Carlsson, E., Ehrenberg, A., \& Ehnfors, M. (2004). Stroke and eating difficulties: Long-term experiences. Journal of Clinical Nursing, 13(7), 825-834.

https://doi.org/10.1111/j.1365-2702.2004.01023.x

Carrión, S., Costa, A., Ortega, O., Verin, E., Clavé, P., \& Laviano, A. (2017). Complications of Oropharyngeal Dysphagia: Malnutrition and Aspiration Pneumonia. In O. Ekberg (Ed.), Dysphagia: Diagnosis and Treatment (pp. 823-857). https://doi.org/10.1007/174_2017_168

Ekberg, O., Hamdy, S., Woisard, V., Wuttge-Hannig, A., \& Ortega, P. (2002). Social and Psychological Burden of Dysphagia: Its Impact on Diagnosis and Treatment. Dysphagia, 17(2), 139-146. https://doi.org/10.1007/s00455-001-0113-5

Elliott, V. (2018). Thinking about the Coding Process in Qualitative Data Analysis. The Qualitative Report, 23(11), 2850-2861.

Farri, A., Accornero, A., \& Burdese, C. (2007). Social importance of dysphagia: Its impact on diagnosis and therapy. Acta Otorhinolaryngologica Italica, 27(2), 83-86.

Folstein, M. F., Folstein, S. E., \& McHugh, P. R. (1975). "Mini-mental state”. Journal of Psychiatric Research, 12(3), 189-198. https://doi.org/10.1016/0022-3956(75)90026-6 
Fusch, P., \& Ness, L. (2015). Are We There Yet? Data Saturation in Qualitative Research. The Qualitative Report, 20(9), 1408-1416.

Helldén, J., Bergström, L., \& Karlsson, S. (2018). Experiences of living with persisting poststroke dysphagia and of dysphagia management - a qualitative study. International Journal of Qualitative Studies on Health and Well-Being, 13(sup1), 1522194. https://doi.org/10.1080/17482631.2018.1522194

Howells, S. R., Cornwell, P. L., Ward, E. C., \& Kuipers, P. (2019a). Dysphagia care for adults in the community setting commands a different approach: Perspectives of speech-language therapists. International Journal of Language \& Communication Disorders, 54(6), 971-981. https://doi.org/10.1111/1460-6984.12499

Howells, S. R., Cornwell, P. L., Ward, E. C., \& Kuipers, P. (2019b). Understanding Dysphagia Care in the Community Setting. Dysphagia, 34(5), 681-691. https://doi.org/10.1007/s00455-018-09971-8

Jacobsson, C., Axelsson, K., Österlind, P. O., \& Norberg, A. (2000). How people with stroke and healthy older people experience the eating process. Journal of Clinical Nursing, 9(2), 255-264. https://doi.org/10.1046/j.1365-2702.2000.00355.x

Karajeh, M. A., Hurlstone, D. P., Patel, T. M., \& Sanders, D. S. (2005). Chefs' knowledge of coeliac disease (compared to the public): A questionnaire survey from the United Kingdom. Clinical Nutrition, 24(2), 206-210. https://doi.org/10.1016/j.clnu.2004.08.006

Larsson, M., Hedelin, B., \& Athlin, E. (2003). Lived experiences of eating problems for patients with head and neck cancer during radiotherapy. Journal of Clinical Nursing, 12(4), 562-570. https://doi.org/10.1046/j.1365-2702.2003.00751.x 
Lisiecka, D., Kelly, H., \& Jackson, J. (2019). How do people with Motor Neurone Disease experience dysphagia? A qualitative investigation of personal experiences. Disability and Rehabilitation, O(0), 1-10. https://doi.org/10.1080/09638288.2019.1630487

Martino, R., Beaton, D., \& Diamant, N. E. (2010). Perceptions of psychological issues related to dysphagia differ in acute and chronic patients. Dysphagia, 25(1), 26-34. https://doi.org/10.1007/s00455-009-9225-0

McQuestion, M., Fitch, M., \& Howell, D. (2011). The changed meaning of food: Physical, social and emotional loss for patients having received radiation treatment for head and neck cancer. European Journal of Oncology Nursing, 15(2), 145-151. https://doi.org/10.1016/j.ejon.2010.07.006

Medin, J., Larson, J., von Arbin, M., Wredling, R., \& Tham, K. (2010). Elderly persons’ experience and management of eating situations 6 months after stroke. Disability and Rehabilitation, 32(16), 1346-1353. https://doi.org/10.3109/09638280903514747

Miller, N., Noble, E., Jones, D., \& Burn, D. (2006). Hard to swallow: Dysphagia in Parkinson's disease. Age and Ageing, 35(6), 614-618. https://doi.org/10.1093/ageing/afl105

Moloney, J., \& Walshe, M. (2018). "I had no idea what a complicated business eating is...": A qualitative study of the impact of dysphagia during stroke recovery. Disability and Rehabilitation, 40(13), 1524-1531. https://doi.org/10.1080/09638288.2017.1300948

Nund, R. L., Ward, E. C., Scarinci, N. A., Cartmill, B., Kuipers, P., \& Porceddu, S. V. (2014a). Carers' Experiences of Dysphagia in People Treated for Head and Neck Cancer: A Qualitative Study. Dysphagia, 29(4), 450-458. https://doi.org/10.1007/s00455-014-9527-8

Nund, R. L., Ward, E. C., Scarinci, N. A., Cartmill, B., Kuipers, P., \& Porceddu, S. V. (2014b). Survivors' experiences of dysphagia-related services following head and 
neck cancer: Implications for clinical practice: Experiences of dysphagia-related services in HNC. International Journal of Language \& Communication Disorders, 49(3), 354-363. https://doi.org/10.1111/1460-6984.12071

Nund, R. L., Ward, E. C., Scarinci, N. A., Cartmill, B., Kuipers, P., \& Porceddu, S. V. (2014c). The lived experience of dysphagia following non-surgical treatment for head and neck cancer. International Journal of Speech-Language Pathology, 16(3), 282289. https://doi.org/10.3109/17549507.2013.861869

Ortlipp, M. (2008). Keeping and Using Reflective Journals in the Qualitative Research Process. The Qualitative Report, 13(4), 695-705.

Ottosson, S., Laurell, G., \& Olsson, C. (2013). The experience of food, eating and meals following radiotherapy for head and neck cancer: A qualitative study. Journal of Clinical Nursing, 22(7-8), 1034-1043. https://doi.org/10.1111/jocn.12151

Patton, M. Q. (2015). Qualitative Research \& Evaluation Methods (4th ed.). Thousand Oaks, CA: SAGE Publications.

Perry, L., \& McLaren, S. (2003). Coping and adaptation at six months after stroke: Experiences with eating disabilities. International Journal of Nursing Studies, 40(2), 185-195. https://doi.org/10.1016/S0020-7489(02)00060-3

Richardson, J., Iezzi, A., Khan, M. A., \& Maxwell, A. (2014). Validity and Reliability of the Assessment of Quality of Life (AQoL)-8D Multi-Attribute Utility Instrument. The Patient, 7(1), 85-96. https://doi.org/10.1007/s40271-013-0036-x

Rumbach, A., Coombes, C., \& Doeltgen, S. (2018). A survey of Australian dysphagia practice patterns. Dysphagia, 33(2), 216-226. https://doi.org/10.1007/s00455-017$9849-4$ 
Sandelowski, M. (2000). Whatever happened to qualitative description? Research in Nursing \& Health, 23(4), 334-340. https://doi.org/10.1002/1098240X(200008)23:4<334::AID-NUR9>3.0.CO;2-G

Seshadri, S., Sellers, C. R., \& Kearney, M. H. (2018). Balancing Eating With Breathing: Community-Dwelling Older Adults' Experiences of Dysphagia and Texture-Modified Diets. The Gerontologist, 58(4), 749-758. https://doi.org/10.1093/geront/gnw203

Silbergleit, A. K., Schultz, L., Jacobson, B. H., Beardsley, T., \& Johnson, A. F. (2012). The Dysphagia Handicap Index: Development and Validation. Dysphagia, 27(1), 46-52. https://doi.org/10.1007/s00455-011-9336-2

Threats, T. (2007). Use of the ICF in Dysphagia Management. Seminars in Speech and Language, 28(4), 323-333. https://doi.org/10.1055/s-2007-986529

United Nations, D. of E. and S. A., Population Division. (2015). World Population Ageing (No. ST/ESA/SER.A/390). Retrieved from http://www.un.org/en/development/desa/population/publications/pdf/ageing/WPA201 5_Report.pdf 
Table I. Participant characteristics $(n=15)$

\begin{tabular}{|c|c|c|c|c|c|c|c|c|}
\hline $\begin{array}{l}\text { Participant } \\
\text { ID }\end{array}$ & Age & Gender & $\begin{array}{l}\text { Employment } \\
\text { status }\end{array}$ & Dysphagia aetiology & $\begin{array}{l}\text { Dysphagia } \\
\text { Handicap } \\
\text { Index } \\
\text { (DHI) } \\
\text { Total }\end{array}$ & $\begin{array}{l}\text { Eating } \\
\text { Assessment } \\
\text { Tool (EAT- } \\
\text { 10) Total }\end{array}$ & $\begin{array}{l}\text { Assessment } \\
\text { of Quality of } \\
\text { Life (AQOL- } \\
\text { 8D) Total } \\
\text { Raw Score }\end{array}$ & $\begin{array}{l}\text { IDDSI } \\
\text { recommendations }\end{array}$ \\
\hline 1 & 81 & $\mathrm{M}$ & Retired & Parkinson's disease & 32 & 8 & 92 & $\begin{array}{l}\text { Regular } \\
\text { Mildly thick }\end{array}$ \\
\hline 2 & 93 & M & Retired & Stroke & 24 & 8 & 87 & $\begin{array}{l}\text { Soft and bite-sized } \\
\text { Mildly thick }\end{array}$ \\
\hline 3 & 73 & M & Retired & Parkinson's disease & 26 & 6 & 79 & $\begin{array}{l}\text { Regular } \\
\text { Thin }\end{array}$ \\
\hline 6 & 71 & M & Retired & Parkinson's disease & 22 & 16 & 78 & $\begin{array}{l}\text { Regular } \\
\text { Thin }\end{array}$ \\
\hline 7 & 74 & M & Part-time & Stroke & 12 & 1 & 69 & $\begin{array}{l}\text { Regular } \\
\text { Mildly thick }\end{array}$ \\
\hline
\end{tabular}




\begin{tabular}{|c|c|c|c|c|c|c|c|c|}
\hline 8 & 78 & $\mathrm{~F}$ & Retired & Parkinson's disease & 62 & 16 & 121 & $\begin{array}{l}\text { Soft and bite-sized } \\
\text { Mildly thick }\end{array}$ \\
\hline 9 & 30 & $\mathrm{~F}$ & Part-time & Stroke & 52 & 19 & 61 & $\begin{array}{l}\text { Soft and bite-sized } \\
\text { Thin }\end{array}$ \\
\hline 10 & 84 & M & Retired & General ageing & 40 & 13 & 83 & $\begin{array}{l}\text { Soft and bite-sized } \\
\text { Mildly thick }\end{array}$ \\
\hline 12 & 74 & $\mathrm{M}$ & Retired & $\begin{array}{l}\text { Base of tongue (BOT) } \\
\text { cancer }\end{array}$ & 58 & 23 & 72 & $\begin{array}{l}\text { Soft and bite-sized } \\
\text { Thin }\end{array}$ \\
\hline 13 & 73 & $\mathrm{~F}$ & Retired & $\begin{array}{l}\text { Multiple System } \\
\text { Atrophy-Cerebellar } \\
\text { (MSA-C) }\end{array}$ & 54 & 17 & 80 & $\begin{array}{l}\text { Soft and bite-sized } \\
\text { Thin }\end{array}$ \\
\hline 15 & 76 & $\mathrm{~F}$ & Retired & Jaw fracture & 48 & 12 & 50 & $\begin{array}{l}\text { Soft and bite-sized } \\
\text { Thin }\end{array}$ \\
\hline
\end{tabular}

